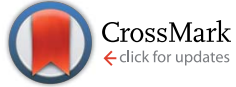

Cite this: RSC Adv., 2016, 6, 34885

Received 8th February 2016

Accepted 30th March 2016

DOI: $10.1039 / c 6 r a 03594 a$

www.rsc.org/advances

\title{
Progression from nano to macro science in soft matter systems: dimers to trimers and oligomers in twist-bend liquid crystals $\uparrow$
}

\author{
Richard J. Mandle* and John W. Goodby \\ In this article we report on the characterization and properties of several unsymmetrical phenyl-benzoate \\ bimesogens that exhibit the soft-matter, twist-bend nematic $\left(\mathrm{N}_{\mathrm{TB}}\right)$ phase. We use this study as a basis to \\ examine the phase behaviour of associated novel trimeric and tetrameric materials, in order to \\ investigate the potential for oligomeric materials to form the $N_{\text {TB }}$ phase. Based on our results we \\ hypothesise that higher oligomers and even polymers are highly likely to exhibit the $\mathrm{N}_{\mathrm{TB}}$ phase, provided \\ they retain a gross bent structure between consecutive mesogenic units. Thus we show at the level of \\ nanoscale organization, dimers can template with respect to one another to form mesophases that are \\ also found in macromolecular systems.
}

\section{Introduction}

The discovery of a new phase of matter lacking lamellar ordering of the molecules while at the same time exhibiting properties associated with such ordering, has motivated a great deal of study into liquid crystal bimesogens and their behaviour. ${ }^{1-19}$ The presently favoured model for this mesophase is that of the 'heliconical twist-bend nematic' phase, predicted independently by Meyer and Dozov, ${ }^{\mathbf{1}, 2}$ in which there exists a helix with extremely tight pitch with the nematic director inclined from the heli-axis by an acute angle., ${ }^{2,9-11}$ This model is experimentally supported by both freeze-fracture TEM studies and carbon $K$-edge SAXS on $\mathrm{CB} 7 \mathrm{CB}$, which allow direct measurement of the nanoscale helix.. ${ }^{10,19}$ The orientational order parameters of the $\mathrm{N}_{\mathrm{TB}}$ phase, determined by polarised Raman spectroscopy as well as ${ }^{2} \mathrm{H}$ and ${ }^{129} \mathrm{Xe} \mathrm{NMR},{ }^{15,16}$ appear to be consistent with the heliconical model of Dosov and Meyer. It should, however, be noted that studies on surface freezing ${ }^{20}$ and ${ }^{2} \mathrm{H}$ NMR have resulted in alternative models. ${ }^{21-23}$

A growing number of materials exist that are known to exhibit the $\mathrm{N}_{\mathrm{TB}}$ phase, ${ }^{\mathbf{2 4 - 2 9}}$ the bulk of which are symmetrical bimesogens possessing a methylene spacer of odd parity. One notable exception is etheric bimesogens, ${ }^{30,31}$ which can be designed to be unsymmetrical in structure by exploiting bifunctional spacer groups, such as bromoalcohols, during chemical synthesis. ${ }^{31}$ Many of the materials known to exhibit the $\mathrm{N}_{\mathrm{TB}}$ phase contain polar functional groups, most often nitriles as in the $\mathrm{CBnCB}$ series of materials. Polar functional

Department of Chemistry, University of York, York, YO10 5DD, UK. E-mail: richard. mandle@york.ac.uk

† Electronic supplementary information (ESI) available. See DOI: 10.1039/c6ra03594a groups can, through dipole-dipole interactions, lead to antiparallel pairing of molecules, ${ }^{32-34}$ with the extent to which this occurs being functional group dependent. This article covers two closely related topics. Firstly we describe how, by moving from symmetrical bimesogens to unsymmetrical, the possibility of stabilising/destabilising the $\mathrm{N}_{\mathrm{TB}}$ phase in methylene linked bimesogens is possible by manipulating the strength of intermolecular interactions, as shown by the target materials in Scheme 1.

Secondly, given that the chemical space surrounding mesogenic dimers that exhibit the twist-bend phase has been somewhat explored, we considered targeting the two oligomeric materials shown in Scheme 2 in the context of the formation and stability of the $\mathrm{N}_{\mathrm{TB}}$ phase.

\section{Experimental}

Full experimental details for the synthesis and characterization of products 1 to 9 are provided in the ESI. $\dagger$ Compounds 3-7 were synthesised, as shown in Scheme 1, via the EDAC/DMAP mediated Steglich esterification between compound 1 (4-(9-(4hydroxyphenyl)nonyl)phenyl 4-cyanobenzoate), prepared as described previously, ${ }^{29}$ and an appropriate benzoic acid.

Fortuitously the chemical intermediate required to prepare unsymmetrical methylene linked phenylbenzoate dimers was also be used as a platform chemical in the synthesis of oligomeric materials, as shown in Scheme 2. ${ }^{29}$ Compound 8 was prepared via the EDAC/DMAP mediated Steglich esterification between compound 1 and 1,4-terephthalic acid (Scheme 2). Compound $\mathbf{9}$ was prepared via the EDAC/DMAP mediated Steglich esterification of compound 1 and 4,4'-(nonane-1,9-diyl) dibenzoic acid. ${ }^{26,29}$ 

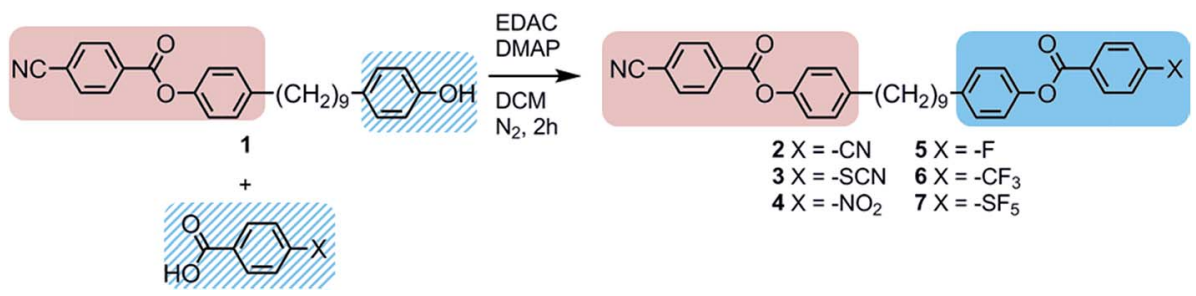

Scheme 1 Target dimeric materials.

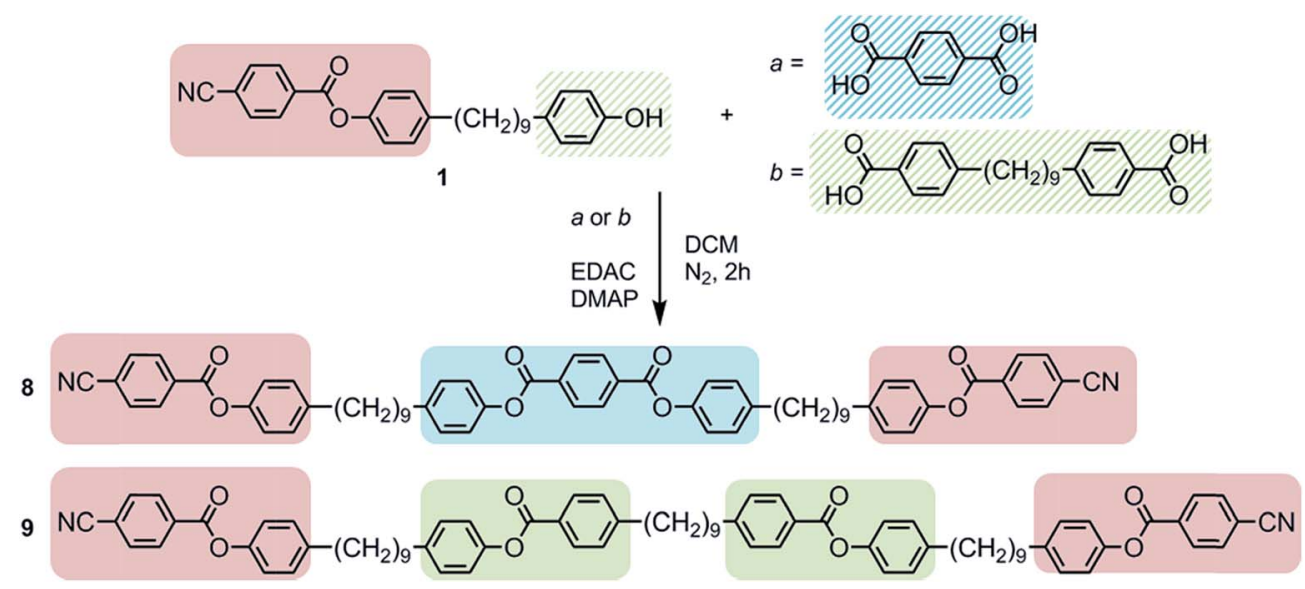

Scheme 2 Target oligomeric materials.

Small angle X-ray scattering was performed on a Bruker D8 Discover equipped with a temperature controlled, bored graphite rod furnace, custom built at the University of York. Computational chemistry was performed at the B3LYP/6-31G(d) level of DFT in Gaussian G09, ${ }^{35}$ with Gaussian output files rendered using Qutemol. ${ }^{36}$ Full experimental details, including chemical characterisation and descriptions of instrumentation used, are available in the ESI. $\dagger$

\section{Results and discussion}

The liquid crystalline properties of the $\mathbf{1}$ and $\mathbf{2}$ were studied by a combination of polarised optical microscopy (POM) and differential scanning calorimetry (DSC), the results for which are presented in Table 1 .

Although compound $\mathbf{1}$ can be described unequivocally as a dimer (or bimesogen), $\mathbf{2}$ is harder to define in such absolute terms due to its ability to form intermolecular hydrogen bonds between the phenol and nitrile groups leading to possible supramolecular oligomeric structures. ${ }^{28,37}$ Whereas 2 has been demonstrated to exhibit nematic and twist-bend nematic phases, ${ }^{26} \mathbf{1}$ was found to exhibit a first order nematic to smectic C phase transition. Phase assignments were made initially by polarised optical microscopy (POM) and then by small angle Xray scattering (SAXS) see Fig. 3, whereas the associated enthalpies and entropies of transitions were determined by differential scanning calorimetry (DSC) as shown in Table 1.

The defect texture observed for the nematic phase of $\mathbf{1}$ showed a classical schlieren texture composed of singularities possessing 2- and 4-brushes, whereas the smectic $\mathrm{C}$ phase exhibited a focal-conic texture that was unbroken, which at first sight could appear as a texture associated with the smectic A phase (Fig. 1a and b). However, X-ray diffraction clearly shows that the smectic phase is tilted (Fig. 1d), and with the combination of the POM studies the phase was unequivocally classified as smectic C. The tilt angle determined from X-ray diffraction was found to reach a maximum of $13^{\circ}$, although as the sample readily crystallises shortly after cooling into the smectic $\mathrm{C}$ phase this value is not saturated.

If we turn now to the properties of the dimers, we can compare those of unsymmetrical structure with the parent symmetrical bimesogen 2, which was found to possess a melting point of $157.6^{\circ} \mathrm{C}$, and monotropic phase transitions from the liquid to the nematic phase at $146.6^{\circ} \mathrm{C}$, and from the nematic to the $\mathrm{N}_{\text {тв }}$ phase at $114.5^{\circ} \mathrm{C}$. In calamitic systems is well known that nitrile terminated materials have a strong tendency to exist as antiparallel correlated pairs or $n$-mers. ${ }^{32,33}$ Contrast this with isothiocyanates, which do not exhibit as large a degree of antiparallel correlation as nitriles, ${ }^{38}$ and with nitro terminated materials, which have a stronger tendency than nitriles to form antiparallel correlated pairs. ${ }^{34}$ As noted in the introduction, moving from symmetrical bimesogens to unsymmetrical variants such as compounds 2-6 (Table 2) allows the possibility of engineering molecules and thus exerting a degree of control over the condensed phases they exhibit by controlling the strength and type of intermolecular interactions. 
Table 1 Transition temperatures $\left(^{\circ}\right)$, associated enthalpies of transition $\left[\mathrm{kJ} \mathrm{mol}^{-1}\right]$ and dimensionless entropies of transition $\{\Delta S / R\}$ for compounds 1 and 2.26,29 Transitions in parenthesis () are monotropic

\begin{tabular}{|c|c|c|c|c|c|c|c|c|c|c|}
\hline No. & $\mathrm{R}$ & $\mathrm{Cr}$ & & SmC & & $\mathrm{N}_{\mathrm{TB}}$ & & $\mathrm{N}$ & & Iso \\
\hline 1 & ${ }^{\cdots} \mathrm{H}$ & - & $\begin{array}{l}109.5 \\
{[47.19]} \\
\{14.85\}\end{array}$ & $(\bullet$ & $\begin{array}{l}61.6 \\
{[3.21]} \\
\{1.15\}\end{array}$ & - & - & $\bullet$ & $\begin{array}{l}71.9) \\
{[1.32]} \\
\{0.46\}\end{array}$ & $\bullet$ \\
\hline 2 & & • & $\begin{array}{l}157.6 \\
{[45.41]} \\
\{12.68\}\end{array}$ & - & - & $(\bullet$ & $\begin{array}{l}114.5 \\
{[0.65]} \\
\{0.20\}\end{array}$ & • & $\begin{array}{l}146.6) \\
{[1.50]} \\
\{0.43\}\end{array}$ & $\bullet$ \\
\hline
\end{tabular}
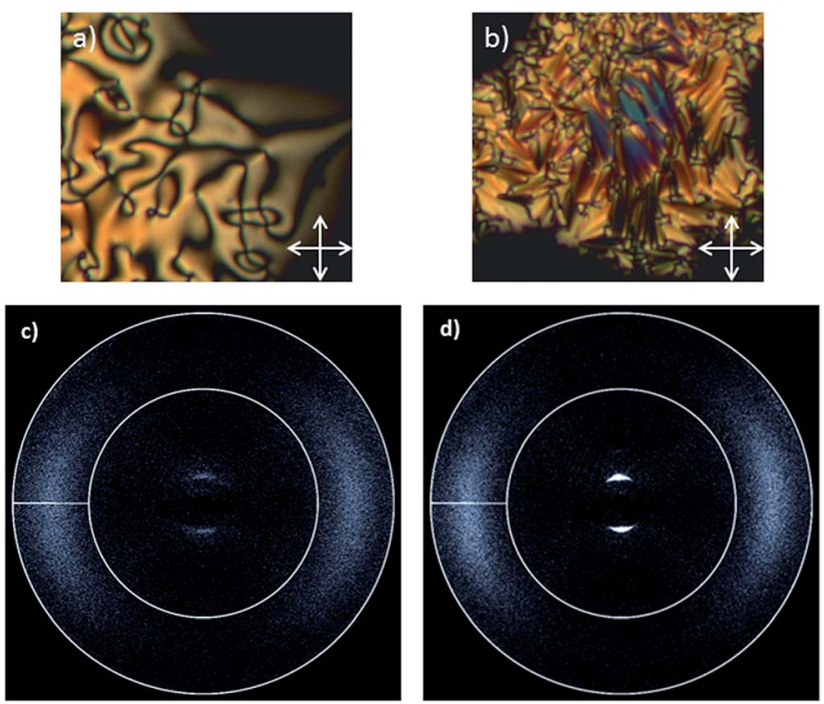

Fig. 1 The schlieren texture of the nematic phase of 1 shown by POM $(\times 100$, area approximately $100 \mu \mathrm{m})\left((\mathrm{a}), 65^{\circ} \mathrm{C}\right)$ and the focal-conic texture of the smectic $C$ phase of $1\left((b), 55^{\circ} \mathrm{C}\right)$ showing numerous focal-conic defects. Small angle X-ray scattering pattern for the nematic phase of $1\left((\mathrm{c}), 63^{\circ} \mathrm{C}\right)$ and the smectic $\mathrm{C}$ phase $\left((\mathrm{d}), 57^{\circ} \mathrm{C}\right)$.

Compounds 2-7 were studied by a combination of POM and DSC and as with the symmetrical parent compound 2 all were found to exhibit nematic and twist-bend nematic mesophases. Representative photomicrographs of both the nematic and $\mathrm{N}_{\mathrm{TB}}$ phases are given in Fig. 2 for compounds 2 and 4. In both cases the nematic phase exhibits a classical nematic schlieren texture, whereas the texture of the $\mathrm{N}_{\mathrm{TB}}$ phase in both cases shows longrange correlations, described as blocks, indicating that the phase is substantially more ordered than the nematic phase that it was derived from paramorphotically.

For compounds 3 and $\mathbf{4}$ both the nematic to isotropic and nematic to $\mathrm{N}_{\mathrm{TB}}$ transition temperatures are close to being an average of those of the two symmetric parent materials that we reported previously, whereas for the unsymmetrical compounds 5 to 7 only one of the symmetrical parent materials (i.e., compound 2) was mesogenic. ${ }^{26}$

The associated enthalpies and entropies of transition for the $\mathrm{N}_{\mathrm{TB}}-\mathrm{N}$ and $\mathrm{N}$-Iso transitions for compounds 3-7 were
Table 2 Transition temperatures $\left({ }^{\circ} \mathrm{C}\right)$ and scaled $\mathrm{N}_{\mathrm{TB}}-\mathrm{N}$ transition temperatures $\left(T_{\mathrm{N}_{\mathrm{TB}} \mathrm{N}} / T_{\mathrm{N}-1}\right)$ for compounds $2-7$. Transitions in parenthesis () are monotropic, i.e. they occur below the melting point of the material

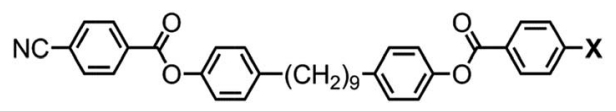

\begin{tabular}{|c|c|c|c|c|c|c|c|c|}
\hline No. & $\mathrm{X}=$ & $\mathrm{Cr}$ & & $\mathrm{N}_{\mathrm{TB}}$ & & $\mathrm{N}$ & & Iso \\
\hline 2 & $-\mathrm{CN}$ & & 157.6 & & 114.5 & & 146.6) & \\
\hline 3 & $-\mathrm{SCN}$ & & 95.6 & & 100.0 & 0 & 123.8 & \\
\hline 4 & $-\mathrm{NO}_{2}$ & & 115.4 & & 100.5) & 0 & 124.9 & \\
\hline 5 & $-\mathrm{F}$ & & 86.2 & & 78.2) & & 95.9 & \\
\hline 6 & $-\mathrm{CF}_{3}$ & & 110.0 & & 69.6 & 0 & 78.3) & \\
\hline 7 & $-\mathrm{SF}_{5}$ & & 102.2 & & 61.1 & 0 & 72.8) & \\
\hline
\end{tabular}
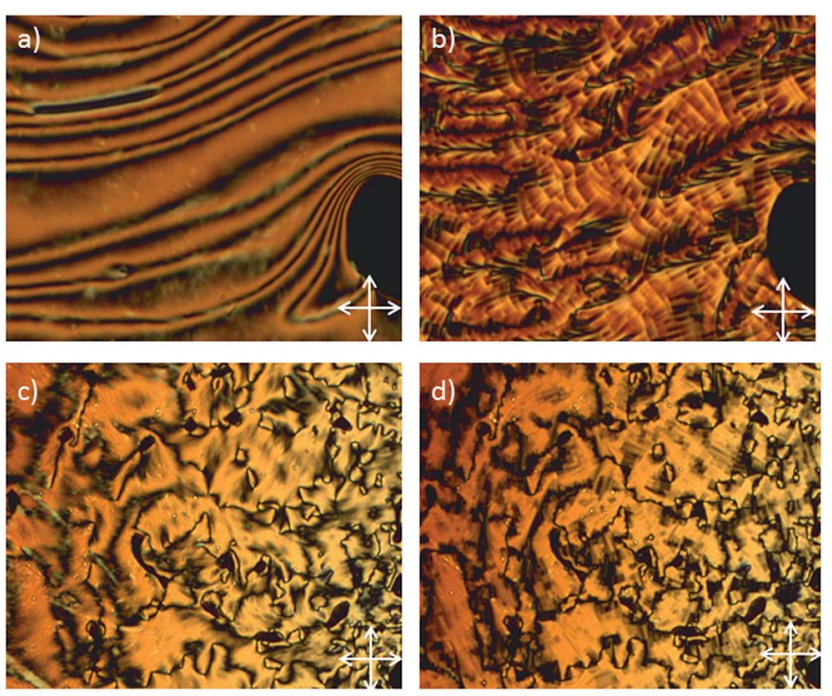

Fig. 2 Photomicrographs ( $\times 100$, area approximately $100 \mu \mathrm{m})$ of the schlieren texture of the nematic phase of compound 4 at $122^{\circ}$ (a), the block-texture of the $\mathrm{N}_{\mathrm{TB}}$ phase of compound 4 at $95{ }^{\circ} \mathrm{C}(\mathrm{b})$, the schlieren texture of the nematic phase of compound 2 at $105^{\circ} \mathrm{C}$ (c) and the block-texture of the $\mathrm{N}_{\text {TB }}$ phase of compound 2 at $95^{\circ} \mathrm{C}$ (d). Both pairs of photomicrographs ( $a$ and b, $c$ and d) present approximately the same region of the sample. 


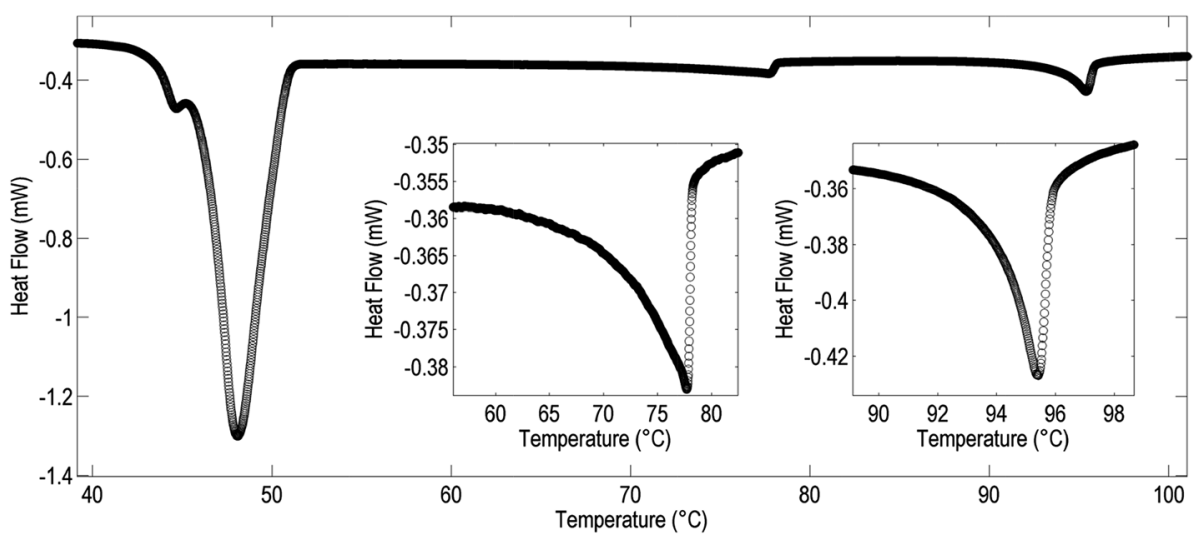

Fig. 3 DSC thermogram $\left(1^{\text {st }} \mathrm{cool}, 10{ }^{\circ} \mathrm{C} \mathrm{min}^{-1}\right.$ ) of compound 5 with expansions showing the isotropic to nematic (right) and nematic to $\mathrm{N}_{\mathrm{TB}}$ phase transitions (left).

determined by DSC at a heat/cool rate of $10{ }^{\circ} \mathrm{C} \mathrm{min}^{-1}$ (see Table 4). Although the nematic to isotropic transition was found to be invariably first order the nematic to $\mathrm{N}_{\mathrm{TB}}$ phase transition was only weakly first order, as reported previously. ${ }^{13}$ The DSC thermogram of 5 on cooling is presented in Fig. 3; thermograms for other compounds are similar and are presented in the ESI. $\dagger$

Curiously for compounds 5 to 7 , which bear fluorine or fluorine containing terminal groups, the associated enthalpy (and thus associated entropy) of the $\mathrm{N}_{\mathrm{TB}}$ to nematic transition is higher than that of the nematic to isotropic (Table 3). This is at odds with all of the other dimeric twist-bend materials that we

Table 3 Associated enthalpies of transition $\left(\Delta H, \mathrm{~kJ} \mathrm{~mol} \mathrm{mo}^{-1}\right)$ and dimensionless entropies of transition $(\Delta S / R)$ for compounds $2-7$

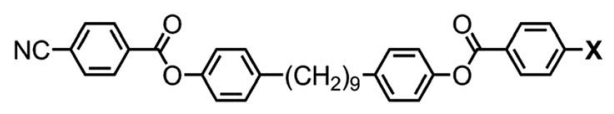

\begin{tabular}{lllllll}
\hline No. & $\mathrm{X}$ & $\Delta H_{\mathrm{N}_{\mathrm{TB}} \mathrm{N}}$ & $\Delta H_{\mathrm{N}-\mathrm{Iso}}$ & $\Delta S_{\mathrm{N}_{\mathrm{TB}}-\mathrm{N}}$ & $\Delta S_{\mathrm{N}-\mathrm{Iso}}$ & $T_{\mathrm{N}_{\mathrm{TB}}-\mathrm{N}} / T_{\mathrm{N}-\mathrm{I}}$ \\
\hline $\mathbf{2}$ & $-\mathrm{CN}$ & 0.65 & 1.50 & 0.20 & 0.43 & 0.923 \\
$\mathbf{3}$ & $-\mathrm{SCN}$ & 0.18 & 0.80 & 0.06 & 0.24 & 0.940 \\
$\mathbf{4}$ & $-\mathrm{NO}_{2}$ & 0.09 & 1.10 & 0.03 & 0.33 & 0.939 \\
$\mathbf{5}$ & $-\mathrm{F}$ & 0.45 & 0.22 & 0.15 & 0.22 & 0.952 \\
$\mathbf{6}$ & $-\mathrm{CF}_{3}$ & 0.89 & 0.42 & 0.31 & 0.15 & 0.975 \\
7 & $-\mathrm{SF}_{5}$ & 0.50 & 0.40 & 0.18 & 0.14 & 0.966
\end{tabular}

Table 4 Transition temperatures $\left({ }^{\circ} \mathrm{C}\right)$, associated enthalpies of transition $\left(\mathrm{kJ} \mathrm{mol}^{-1}\right)$ and dimensionless entropies of transition for compound 8

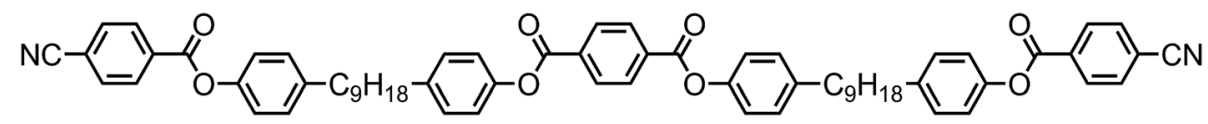

\begin{tabular}{lcrr}
\hline & $\mathrm{Cr}-\mathrm{N}_{\mathrm{TB}}$ & $\mathrm{N}_{\mathrm{TB}}-\mathrm{N}$ & $\mathrm{N}-\mathrm{Iso}$ \\
\hline$T\left({ }^{\circ} \mathrm{C}\right)$ & 146.5 & 164.2 & 210.3 \\
$\Delta H\left(\mathrm{~kJ} \mathrm{~mol}^{-1}\right)$ & 41.58 & 0.29 & 2.56 \\
$\Delta S / R$ & 11.92 & 0.08 & 0.64
\end{tabular}

are aware of, although similar behaviour has been reported in an oligomeric system. ${ }^{29}$ Conversely, compounds 2 to 4 display classical behaviour, with the associated enthalpy/entropy of the $\mathrm{N}_{\mathrm{TB}}-\mathrm{N}$ transition being smaller than that of the $\mathrm{N}-\mathrm{I}$ transition. The scaled transition temperature, $T_{\mathrm{N}_{\mathrm{TB}}-\mathrm{N}} / T_{\mathrm{N}-\mathrm{I}}$, for compounds 2 to 7 were shown to be not particularly diagnostic, with each material having values of similar magnitude.

With a great deal of chemical space concerning dimers and bimesogens now explored in the context of the $\mathrm{N}_{\mathrm{TB}} / \mathrm{N}_{\mathrm{X}}$ phase $^{25-27,30,31}$ it is perhaps inevitable that future synthetic work will shift beyond simple mesogenic dimers. Trimers are the logical progression from dimers, and it is already known that these systems can exhibit the $\mathrm{N}_{\mathrm{TB}} / \mathrm{N}_{\mathrm{X}}$ phase; Jansze et al. described a novel hydrogen bonded trimer, ${ }^{\mathbf{2 8 , 3 9 , 4 0}}$ whereas Wang et al. reported a trimer composed of two cyanobiphenyl units appended to an oxadiazole bent core. ${ }^{41}$ In this study trimer 8 was formed by the esterification of $\mathbf{1}$ and terephthalic acid, and is the first covalently bonded, linear trimer to exhibit the $\mathrm{N}_{\mathrm{TB}}$ phase. The transition temperatures, associated enthalpies and entropies of compound $\mathbf{8}$ of transition are given in Table 4.

On cooling compound $\mathbf{8}$ from the isotropic liquid a clean schlieren texture could be observed by POM (Fig. 4a). Further cooling into the $\mathrm{N}_{\mathrm{TB}}$ phase yielded a transition to the classical blocky texture (Fig. 4b and c). The degree of supercooling was rather short, with the material recrystallizing in the region of 130-135 ${ }^{\circ} \mathrm{C}$. In both phases the material was highly viscous and a large amount of manual force was required to shear the 

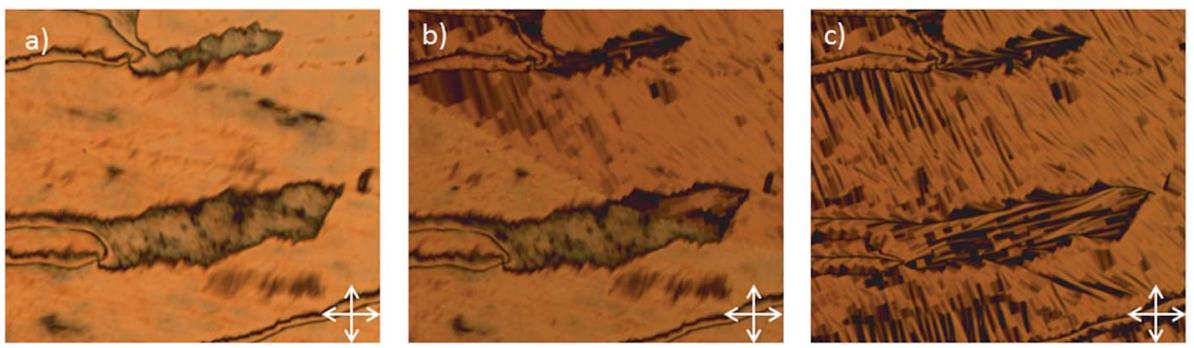

Fig. 4 Photomicrographs $(\times 100$, area approximately $100 \mu \mathrm{m})$ of the schlieren texture of the nematic phase of compound 7 at $179{ }^{\circ} \mathrm{C}(\mathrm{a})$, the nematic to $\mathrm{N}_{\mathrm{TB}}$ transition at $164^{\circ} \mathrm{C}$ (b) and the blocky-texture of the $\mathrm{N}_{\mathrm{TB}}$ phase of compound 8 at $160{ }^{\circ} \mathrm{C}$. (c) All photomicrographs present approximately the same region of the sample.

Table 5 Transition temperatures $\left({ }^{\circ} \mathrm{C}\right)$, associated enthalpies of transition $\left(\mathrm{kJ} \mathrm{mol}^{-1}\right)$ and dimensionless associated entropies of transition of compound 9 (ref. 29)

\begin{tabular}{|c|c|c|c|}
\hline & $\mathrm{Cr}-\mathrm{N}_{\mathrm{TB}}$ & $\mathrm{N}_{\mathrm{TB}}-\mathrm{N}$ & N-Iso \\
\hline$T\left({ }^{\circ} \mathrm{C}\right)$ & 113.6 & 127.7 & 141.5 \\
\hline
\end{tabular}
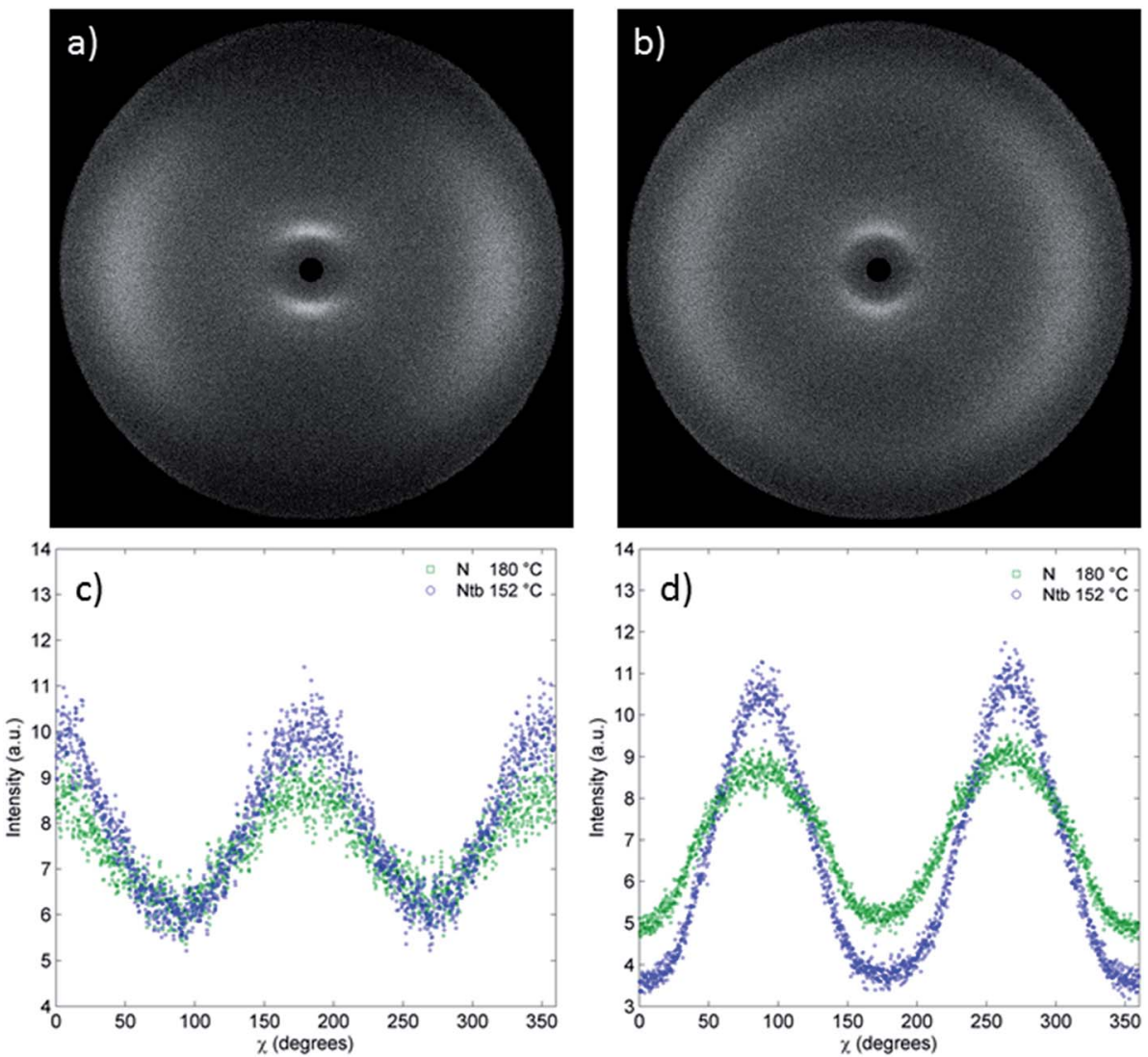

Fig. 5 Two dimensional small angle $X$-ray scattering (SAXS) patterns for compound 8 in the nematic phase $\left((a), 180{ }^{\circ} \mathrm{C}\right)$ and the $\mathrm{N}_{\mathrm{TB}}$ phase $((\mathrm{b})$, $152^{\circ} \mathrm{C}$ ) along with the distribution of the small angle $\chi \operatorname{scan}((\mathrm{c}), 2 \theta=3-15)$ and the wide angle $\chi \operatorname{scan}((\mathrm{d}), 2 \theta=15-25)$. 
sample. This qualitatively high viscosity is a consequence of the material being intercalated, as reported for other dimers. ${ }^{13}$

Extending the oligomeric form resulted in the preparation of compound 9, which is the first tetramer to exhibit the twistbend nematic phase; a full account of its behaviour has recently been given. ${ }^{29}$ However, unlike oligomeric materials such as compound $\mathbf{9}$ (Table 5), for compound $\mathbf{8}$ the entropy and enthalpy associated with the twist-bend nematic to nematic phase transition was found to be around an order of magnitude lower than that for the nematic to isotropic liquid transition. Thus, the transitional behaviour of $\mathbf{8}$ appears to be closer to that of dimeric materials than that of the oligomer $\mathbf{9}$.

The nematic and twist-bend nematic phases of compound 8 were studied by small angle X-ray scattering (Fig. 5) over a temperature range of $207-141{ }^{\circ} \mathrm{C}$ with data collected in $3{ }^{\circ} \mathrm{C}$ steps, the experimental setup for which is described in the ESI. $\dagger$ Two dimensional X-ray scattering patterns for compound 8 in the nematic phase at $180{ }^{\circ} \mathrm{C}$ and the $\mathrm{N}_{\mathrm{TB}}$ phase at $152{ }^{\circ} \mathrm{C}$ are presented in Fig. $5 \mathrm{a}$ and $\mathrm{b}$ respectively.

In the small angle region $(2 \theta=3-15)$ a moderate reduction $(<0.5 \AA)$ was observed in the $d$-spacing at the nematic to $\mathrm{N}_{\mathrm{TB}}$ phase transition. Tabulated values of $d$-spacings are given in the ESI. $\dagger$ This reduction in $d$-spacing is accompanied by a decrease in the scattered intensity at small angles relative to the nematic phase (Fig. 5c). Previously such a reduction in $d$-spacing has been reported to be a consequence of the molecules tilting away from the helix axis of the $\mathrm{N}_{\mathrm{TB}}$ phase. ${ }^{9}$ Although the nematic phase of 8 is well aligned by the magnetic field employed during SAXS studies the $\mathrm{N}_{\text {тв }}$ phase is only partly aligned, this results in the reduction in scattered intensities at $\chi=90^{\circ}$ and $270^{\circ}$ and the increase in scattered intensities at $\chi=0^{\circ}$ and $180^{\circ}$ (Fig. $5 \mathrm{c}$ and d).

The wide-angle peak corresponding to the average lateral molecular separation is more defined in the nematic phase than in the $\mathrm{N}_{\mathrm{TB}}$ phase. On entering the $\mathrm{N}_{\mathrm{TB}}$ phase there is a small reduction in the $d$-spacing $(<0.2 \AA)$ of this peak, however the definition is actually reduced relative to that in the nematic phase, as shown by the distribution of the wide angle scattering peak $(2 \theta=15-25)$ about $\chi$ in Fig. 5 d.

Thus when studied by SAXS compound 8 behaves similarly to other bimesogenic materials that exhibit the $\mathrm{N}_{\mathrm{TB}}$ phase. However the behaviour of $\mathbf{8}$ is in contrast to the oligomeric compound 9, which lacks the discrete reduction in $d$-spacing associated with the small angle scattering peak at the $\mathrm{N}-\mathrm{N}_{\mathrm{TB}}$ transition, and instead exhibits a continuous increase with decreasing temperature. ${ }^{29}$ Furthermore, for compound 9 there is almost no change in the intensity in the $\chi$ scan in either the small angle $(2 \theta=3-15)$ or wide angle $(2 \theta=15-25)$ regions of the scattering pattern (Fig. 6c and d) which is a consequence of both the nematic and $\mathrm{N}_{\mathrm{TB}}$ phases being well aligned by the external magnetic field.

Molecular modelling was used to try to rationalise how the observed $d$-spacing of the small angle peak, $21 \AA$, relates to the
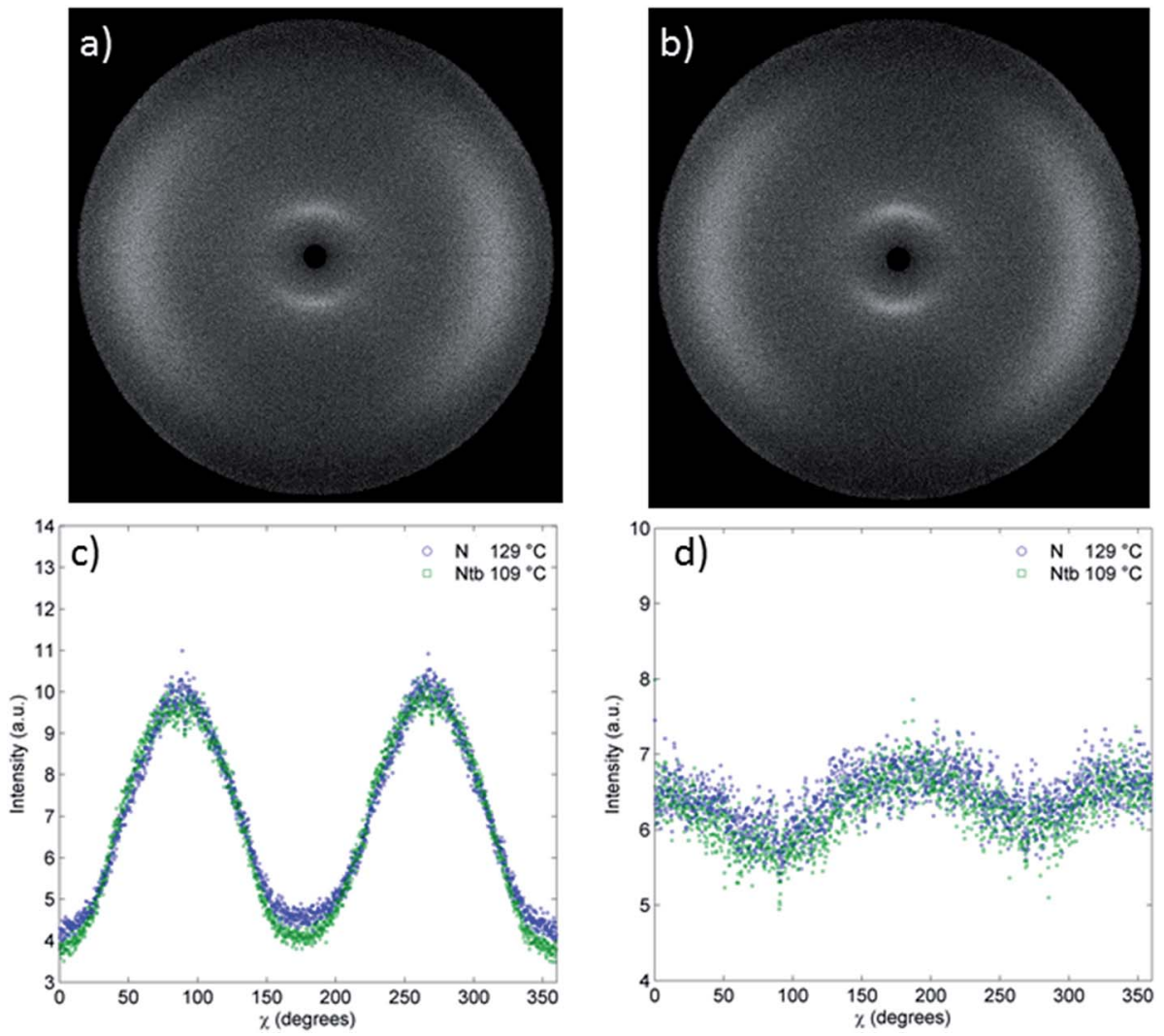

Fig. 6 Two dimensional small angle $X$-ray scattering patterns for compound 9 in the nematic phase $\left((a), 129^{\circ} \mathrm{C}\right)$ and the $\mathrm{N}_{\text {TB }}$ phase $\left((\mathrm{b}), 109{ }^{\circ} \mathrm{C}\right)$ along with the distribution of the wide angle $\chi \operatorname{scan}((\mathrm{c}), 2 \theta=15-25)$ and small angle $\chi$ scan ((d), $2 \theta=3-15)$. 

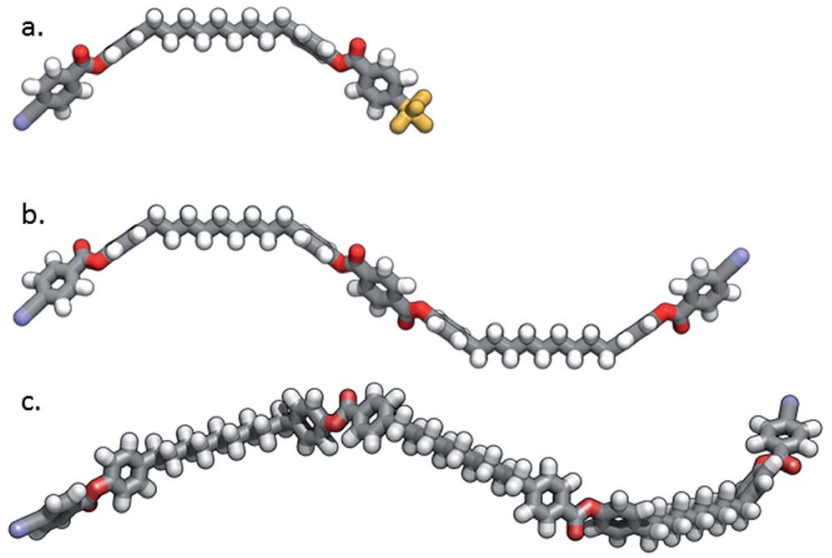

Fig. 7 The B3LYP/6-31G(d) minimised geometry of compound 7 (a), of compound 8 (b) and of compound 9 (c).

molecular length of $\mathbf{8}$ which was estimated to be significantly larger than this figure. The B3LYP/6-31G(d) minimised geometry of $\mathbf{8}$ is shown in Fig. 7. The end-to-end molecular length, as determined from the minimised geometry, of compound $\mathbf{8}$ is $\mathbf{5 8}$ $\AA$, predictably larger than a simple dimer such as $7(32 \AA)$. The measured $d$-spacing for 8 corresponds to 0.37 times the full molecular length, indicating that, unsurprisingly, there is extensive intercalation of the molecules in both the nematic and $\mathrm{N}_{\text {Тв }}$ phases. This manifests in the sample having a qualitatively high viscosity, which was evident during microscopy when attempting to mechanically shear the sample. Similarly, the $d$-spacing observed for the small angle peak in compound 9 is around $1 / 4^{\text {th }}$ of the molecular end-to-end length, ${ }^{29}$ indicating that both the nematic and $\mathrm{N}_{\mathrm{TB}}$ phases are also extensively intercalated. This is in analogy to behaviour observed in other tetrameric and trimeric materials. ${ }^{42,43}$

As shown in Fig. 7, the minimum energy geometry of 9 is helical due to the non-linearity of the phenylbenzoate mesogenic units. In contrast to this, the minimum energy geometry of $\mathbf{8}$ is linear due to the presence of a phenyl terephthalate mesogenic unit in the centre of the molecule. The linear shape of $\mathbf{8}$ is only preserved in the conformer where all methylene groups in both spacers are trans; any deviation from this breaks the plane of symmetry and results in left- and right-handed helical conformers that are degenerate.

\section{Conclusions}

For the unsymmetrical bimesogens, we have demonstrated that it is possible to incorporate functional groups that are normally detrimental to mesomorphic properties for dimers while retaining the twist-bend nematic phase. The pentafluorosulphanyl group $\left(-\mathrm{SF}_{5}\right)$ is highly polar, yet gives notoriously low clearing points due to its sheer bulk and polarity. ${ }^{44,45}$ Yet the $\mathrm{SF}_{5}$ group can be incorporated into an unsymmetrical bimesogen and retain the mesomorphic state. The thermal stability of the twist-bend nematic phase is highest when the polar group is conjugated to the core $\left(-\mathrm{CN}>-\mathrm{NO}_{2} \gg-\mathrm{F}\right)$. However, non-conjugated groups can also support the $\mathrm{N}_{\mathrm{TB}}$ phase albeit with reduced thermal stability $\left(-\mathrm{SCN} \gg-\mathrm{CF}_{3}>\right.$ $-\mathrm{SF}_{5}$ ). It is worth noting that in symmetrical systems all polar groups other than nitrile and isothiocyanates resulted in the materials being non-mesogenic $\left(\mathrm{NO}_{2}, \mathrm{~F}, \mathrm{CF}_{3}, \mathrm{SF}_{5}\right){ }^{26}$

The twist-bend nematic phase has been observed in both polar and non-polar symmetrical dimers. ${ }^{25,26}$ It therefore seems probable that unsymmetrical bimesogens with one polar and one non-polar group will exhibit this phase. The ability to incorporate the bulky $-\mathrm{SF}_{5}$ group whilst still retaining the twistbend nematic phase has implications for the experimental study of the local structure of the $\mathrm{N}_{\mathrm{TB}}$ phase as it raises the possibility of incorporating specific molecular features as probes to aid investigations of the local structure of the mesophase. Possible examples include materials that are unsymmetrically deuterated for ${ }^{2} \mathrm{H}$ NMR, reactive mesogens for polymer stabilised twist-bend nematics and incorporating fluorescent dyes for imaging.

Secondly, for the oligomeric twist-bend materials, it appears that the driving force behind the formation of the $\mathrm{N}_{\mathrm{TB}}$ phase is molecular shape and the minimisation of free volume..$^{46,47}$ Based on this we hypothesise that higher oligomers and even polymers are highly likely to exhibit the $\mathrm{N}_{\mathrm{TB}}$ phase, provided they retain a gross bent or twisted structure between consecutive mesogenic units. Indeed, there has been suggestion and much discussion that the twist-bend phase may have originally been observed in polymers long before its discovery in simple dimeric materials. ${ }^{48}$ However, as with dimers and bimesogens, the specific angle between subsequent mesogenic units may dictate the incidence or absence of the twist-bend nematic phase in such materials and may explain its absence until recently in linear oligomers. ${ }^{28,41}$

\section{Acknowledgements}

We would like to thank the Engineering and Physical Sciences Research Council (EPSRC) for support of this work via grant codes EP/K039660/1 and EP/M020584/1. Raw data are available upon request from the University of York data catalogue.

\section{References}

1 R. B. Meyer, Structural Problems in Liquid Crystal Physics, in Les Houches Summer School in Theoretical Physics, 1973. Molecular Fluids, ed. R. Balian and G. Weil, Gordon and Breach, New York, 1976, pp. 273-373.

2 I. Dozov, On the Spontaneous Symmetry Breaking in the Mesophases of Achiral Banana-Shaped Molecules, Europhys. Lett., 2001, 56, 247-253.

3 M. Šepelj, A. Lesac, U. Baumeister, S. Diele, H. Loc Nguyen and D. W. Bruce, Intercalated liquid-crystalline phases formed by symmetric dimers with an $\alpha, \omega$-diiminoalkylene spacer, J. Mater. Chem., 2006, 17, 1154-1165.

4 V. P. Panov, M. Nagarai, J. K. Vij, Y. P. Panarin, A. Kohlmeier, M. G. Tamba, R. A. Lewis and G. H. Mehl, Spontaneous Periodic Deformations in Nonchiral Planar-Aligned Bimesogens with a Nematic-Nematic Transition and 
a Negative Elastic Constant, Phys. Rev. Lett., 2010, 105, 167701.

5 M. Cestari, S. Diez-Berart, D. A. Dunmur, A. Ferrarini, M. R. de la Fuente, D. J. B. Jackson, D. O. Lopez, G. R. Luckhurst, M. A. Perez-Jubindo, R. M. Richardson, J. Salud, B. A. Timimi and H. Zimmermann, Phase Behaviour and Properties of the Liquid-Crystal Dimer $1^{\prime \prime}, 7^{\prime \prime}$-bis(4-cyanobiphenyl 4'-yl) heptane: A Twist-Bend Nematic Liquid Crystal, Phys. Rev. E: Stat., Nonlinear, Soft Matter Phys., 2011, 84, 031704.

6 C. S. P. Tripathi, P. Losada-Pérez, C. Glorieux, A. Kohlmeier, M. G. Tamba, G. H. Mehl and J. Leys, Nematic-Nematic Phase Transition in the Liquid Crystal Dimer CB9CB and its Mixtures with 5CB: A High-Resolution Adiabatic Scanning Calorimetric Study, Phys. Rev. E: Stat., Nonlinear, Soft Matter Phys., 2011, 84, 041707.

7 V. P. Panov, R. Balachandran, M. Nagaraj, J. K. Vij, M. G. Tamba, A. Kohlmeier and G. H. Mehl, Microsecond Linear Optical Response in the Unusual Nematic Phase of Achiral Bimesogens, Appl. Phys. Lett., 2011, 99, 261903.

8 P. A. Henderson and C. T. Imrie, Methylene-Linked Liquid Crystal Dimers and the Twist-Bend Nematic Phase, Liq. Cryst., 2011, 38, 1407-1414.

9 V. Borshch, Y.-K. Kim, J. Xiang, M. Gao, A. Jákli, V. P. Panov, J. K. Vij, C. T. Imrie, M. G. Tamba, G. H. Mehl and O. D. Lavrentovich, Nematic Twist-Bend Phase with Nanoscale Modulation of Molecular Orientation, Nat. Commun., 2013, 4, 2635.

10 D. Chen, J. H. Porda, J. B. Hooper, A. Klittnic, Y. Shen, M. R. Tuchband, E. Korblova, D. Bedrov, D. M. Walba, M. A. Glaser, J. E. Maclennan and N. A. Clark, A TwistBend Chiral Helix of $8 \mathrm{~nm}$ Pitch in a Nematic Liquid Crystal of Achiral Molecular Dimers, Proc. Natl. Acad. Sci. U. S. A., Early Ed., 2013, 110, 15931-15936.

11 D. Chen, M. Nakata, R. Shao, M. R. Tuchband, M. Shuai, U. Baumeister, W. Weissflog, D. M. Walba, M. A. Glaser, J. E. Maclennan and N. A. Clark, Twist-Bend Heliconical Chiral Nematic Liquid Crystal Phase of an Achiral Rigid Bent-Core Mesogen, Phys. Rev. E: Stat., Nonlinear, Soft Matter Phys., 2014, 89, 022506.

12 S. M. Salili, C. Kim, C. Sprunt, J. T. Gleeson, O. Parri and A. Jákli, Flow Properties of a Twist-Bend Nematic Liquid Crystal, RSC Adv., 2014, 4, 57419-57423.

13 R. J. Mandle, E. J. Davis, C. T. Archbold, S. J. Cowling and J. W. Goodby, Microscopy Studies of the Nematic $\mathrm{N}_{\mathrm{TB}}$ phase of 1,11-Di-(1" $1^{\prime \prime}$-cyanobiphenyl-4-yl)undecane, J. Mater. Chem. C, 2014, 2, 556-566.

14 R. Balachandran, V. P. Panov, Y. P. Panarin, J. K. Vij, M. G. Tamba, G. H. Mehl and J. K. Song, Flexoelectric Behavior of Bimesogenic Liquid Crystals in the Nematic Phase - Observation of a New Self-Assembly Pattern at the Twist-Bend Nematic and the Nematic Interface, J. Mater. Chem. C, 2014, 2, 8179-8184.

15 Z. Zhang, V. P. Panov, M. Nagaraj, R. J. Mandle, J. W. Goodby, G. R. Luckhurst, J. C. Jones and H. F. Gleeson, Raman scattering studies of order parameters in liquid crystalline dimers exhibiting the nematic and twist-bend nematic phases, J. Mater. Chem. C, 2015, 3, 10007-10016.

16 J. P. Jokisaari, G. R. Luckhurst, B. A. Timimi, J. Zhu and H. Zimmermann, Twist-bend nematic phase of the liquid crystal dimer CB7CB: orientational order and conical angle determined by ${ }^{129} \mathrm{Xe}$ and ${ }^{2} \mathrm{H}$ NMR Spectroscopy, Liq. Cryst., 2015, 42, 708-721, DOI: 10.1080/02678292.2015.1037576.

17 L. Bequin, J. W. Emsley, M. Lelli, A. Lesage, G. R. Luckhurst, B. A. Timimi and H. Zimmermann, The Chirality of a TwistBend Nematic Phase Identified by NMR Spectroscopy, $J$. Phys. Chem. B, 2012, 116, 7940-7951.

18 C. T. Archbold, E. J. Davis, R. J. Mandle, S. J. Cowling and J. W. Goodby, Chiral dopants and the twist-bend nematic phase - induction of novel mesomorphic behaviour in an apolar bimesogen, Soft Mater., 2015, 11, 7547-7557.

19 C. Zhu, M. R. Tuchband, A. Young, M. Shuai, A. Scarbrough, D. M. Walba, J. E. Maclennan, C. Wang, A. Hexemer and N. A. Clark., Resonant carbon $K$-edge soft X-ray scattering from lattice-free heliconical molecular ordering: soft dilative elasticity of the twist-bend liquid crystal phase, arXiv:1512.08340 [cond-mat.soft], 2016.

20 E. Gorecka, M. Salmonczyk, A. Zep, D. Pociecha, C. Welch, Z. Ahmed and G. H. Mehl, Do the Short Helices Exist in the Nematic TB Phase, Liq. Cryst., 2015, 42, 1-7.

21 A. Hoffmann, A. G. Vanakaras, A. Kohlmeier, G. H. Mehl and D. J. Photinos, On The Structure of the $\mathrm{N}_{\mathrm{X}}$ Phase of Symmetric Dimers: Inferences from NMR, Soft Matter, 2015, 11, 850-855, DOI: 10.1039/c4sm02480j.

22 A. G. Vanakaras and D. J. Photinos, A molecular theory of nematic-nematic phase transitions in mesogenic dimers, Soft Matter, 2016, 12, 2208-2220.

23 T. Ivšić, M. Vinković, U. Baumeister, A. Mikleušević and A. Lesac, Towards understanding the $\mathrm{N}_{\mathrm{TB}}$ phase: a combined experimental, computational and spectroscopic study, RSC Adv., 2016, 6, 5000-5007, DOI: 10.1039/c5ra26078g.

24 A. Zep, S. Aya, K. Aihara, K. Ema, D. Pociecha, K. Madrak, P. Bernatowicz, H. Takezoe and E. Gorecka, Multiple nematic phases observed in chiral mesogenic dimers, $J$. Mater. Chem. C, 2013, 1, 46-49.

25 R. J. Mandle, E. J. Davis, C. T. Archbold, C. C. A. Voll, J. L. Andrews, S. J. Cowling and J. W. Goodby, Apolar Bimesogens and the Incidence of the Twist-Bend Nematic Phase, Chem.-Eur. J., 2015, 21, 8158-8167.

26 R. J. Mandle, E. J. Davis, C. C. A. Voll, C. T. Archbold, J. W. Goodby and S. J. Cowling, The Relationship between Molecular Structure and the Incidence of the $\mathrm{N}_{\mathrm{TB}}$ Phase, Liq. Cryst., 2015, 42, 688-703, DOI: 10.1080/ 02678292.2014.974698.

27 E. Gorecka, N. Vaupotič, A. Zep, D. Pochiecha, J. Yoshioka, J. Yamamoto and H. Takazoe, A Twist-Bend Nematic $\left(\mathrm{N}_{\mathrm{TB}}\right)$ Phase of Chiral Materials, Angewandte, 2015, 54, 1015510159.

28 S. M. Jansze, A. Martínez-Felipe, J. D. M. Storey, A. T. M. Marcelis and C. T. Imrie, A Twist-Bend Nematic Phase Driven by Hydrogen Bonding, Angew. Chem., Int. Ed., 2015, 54, 643-646. 
29 R. J. Mandle and J. W. Goodby, A Liquid Crystalline Oligomer Exhibiting Nematic and Twist-Bend Nematic Mesophases, ChemPhysChem, 2016, 7, 967-970.

30 R. J. Mandle, E. J. Davis, S. A. Lobato, C. C. A. Vol, S. J. Cowling and J. W. Goodby, Characterisation of an Unsymmetrical, Ether-linked, Fluorinated Bimesogen Exhibiting a New Polymorphism Containing the $\mathrm{N}_{\mathrm{TB}}$ or 'Twist-Bend' Phase, Phys. Chem. Chem. Phys., 2014, 16, 6907-6915.

31 R. J. Mandle, C. C. A. Voll, D. J. Lewis and J. W. Goodby, Etheric Bimesogens and the Twist-Bend Nematic Phase, Liq. Cryst., 2015, 43, 13-21, DOI: 10.1080/ 02678292.2015.1091095.

32 G. W. Gray and J. E. Lydon, New Type of Smectic Mesophase?, Nature, 1974, 252, 221-222.

33 A. J. Leadbetter, J. C. Frost, J. P. Gaughan, G. W. Gray and A. Mosely, The Structure of Smectic A Phases of Compounds with Cyano End Groups, J. Phys., 1979, 40, 375-380.

34 R. J. Mandle, S. J. Cowling, I. Sage, M. E. Colclough and J. W. Goodby, Relationship between Molecular Association and Re-entrant Phenomena in Polar Calamitic Liquid Crystals, J. Phys. Chem. B, 2015, 119, 3273-3280.

35 M. J. Frisch, G. W. Trucks, H. B. Schlegel, G. E. Scuseria, M. A. Robb, J. R. Cheeseman, G. Scalmani, V. Barone, B. Mennucci, G. A. Petersson, H. Nakatsuji, M. Caricato, X. Li, H. P. Hratchian, A. F. Izmaylov, J. Bloino, G. Zheng, J. L. Sonnenberg, M. Hada, M. Ehara, K. Toyota, R. Fukuda, J. Hasegawa, M. Ishida, T. Nakajima, Y. Honda, O. Kitao, H. Nakai, T. Vreven, J. A. Montgomery Jr, J. E. Peralta, F. Ogliaro, M. Bearpark, J. J. Heyd, E. Brothers, K. N. Kudin, V. N. Staroverov, R. Kobayashi, J. Normand, K. Raghavachari, A. Rendell, J. C. Burant, S. S. Iyengar, J. Tomasi, M. Cossi, N. Rega, J. M. Millam, M. Klene, J. E. Knox, J. B. Cross, V. Bakken, C. Adamo, J. Jaramillo, R. Gomperts, R. E. Stratmann, O. Yazyev, A. J. Austin, R. Cammi, C. Pomelli, J. W. Ochterski, R. L. Martin, K. Morokuma, V. G. Zakrzewski, G. A. Voth, P. Salvador, J. J. Dannenberg, S. Dapprich, A. D. Daniels, Ö. Farkas, J. B. Foresman, J. V. Ortiz, J. Cioslowski and D. J. Fox, Gaussian 09, Revision D.01, Gaussian, Inc., Wallingford, CT, 2009.

36 M. Tarini, P. Cignoni and C. Montani, Ambient Occlusion and Edge Cueing for Enhancing Real Time Molecular Visualization, IEEE Trans. Visual. Comput. Graph., 2006, 12, 1237-1244.
37 C. T. Imrie and P. A. Henderson, Liquid Crystal Dimers and Higher Oligomers: Between Monomers and Polymers, Chem. Soc. Rev., 2007, 36, 2096-2124.

38 D. Sinha, P. K. Mandal and R. Dabrowski, Structural, optical and dynamical properties of a high birefringence laterally fluorinated terphenyl isothiocyanate, Phase Transitions, 2015, 88, 153-168.

39 D. A. Paterson, A. Martinez-Felipe, S. M. Jansze, A. T. M. Marcelis, J. M. D. Storey and C. T. Imrie, New insights into the liquid crystal behaviour of hydrogenbonded mixtures provided by temperature-dependent FTIR spectroscopy, Liq. Cryst., 2015, 42, 928-939.

40 A. Martinez-Felipe and C. T. Imrie, The role of hydrogen bonding in the phase behaviour of supramolecular liquid crystal dimers, J. Mol. Struct., 2015, 1100, 429-437.

41 Y. Wang, G. Singh, D. M. Agra-Kooijman, M. Gao, H. K. Bisoyi, C. Xue, M. R. Fisch, S. Kumar and Q. Li, Room temperature heliconical twist-bend nematic liquid crystal, CrystEngComm, 2015, 1, 2778-2782.

42 C. T. Imrie, D. Steward, C. Remy, D. W. Christie, I. W. Hamley and R. Harding, Liquid Crystal Tetramers, J. Mater. Chem., 1999, 9, 2321-2325.

43 C. T. Imrien, P. A. Henderson and J. M. Seddon, Nonsymmetric Liquid Crystal Trimers. The First Example of a Triply-Intercalated Alternating Smectic C Phase, J. Mater. Chem., 2004, 14, 2486-2488.

44 P. Kirsch, M. Bremer, M. Heckmeier and K. Tarumi, Liquid Crystals Based on Hypervalent Sulfur Fluorides: Pentafluorosulfanyl as Polar Terminal Group, Angew. Chem., Int. Ed., 1999, 38, 1989-1992.

45 P. Kirsch and M. Bremer, Nematic Liquid Crystals for Active Matrix Displays: Molecular Design and Synthesis, Angew. Chem., Int. Ed., 2000, 39, 4216-4235.

46 J. W. Goodby, E. J. Davis, R. J. Mandle and S. J. Cowling, Nano-Segregation and Directed Self-Assembly in the Formation of Functional Liquid Crystals, Isr. J. Chem., 2012, 52, 863-880.

47 J. W. Goodby, R. J. Mandle, E. J. Davis, T. Zhong and S. J. Cowling, What Makes a Liquid Crystal? The Effect of Free Volume on Soft Matter, Liq. Cryst., 2015, 42, 593-622.

48 G. Ungar, V. Percec and M. Zuber, Liquid crystalline polyethers based on conformational isomerism. 20. Nematic-nematic transition in polyethers and copolyethers based on 1-(4-hydroxyphenyl)2-(2-R-4-hydroxyphenyl)ethane with $\mathrm{R}=$ fluoro, chloro and methyl and flexible spacers containing an odd number of methylene units, Macromolecules, 1992, 25, 75-80. 